\title{
Research on Harms and Governance of Internet Rumors
}

\author{
Xijuan Liu ${ }^{1}, \mathrm{Pu} \mathrm{Li}{ }^{2}$, Mingjie Zhou ${ }^{3}$, Chengcheng $\mathrm{Li}^{2}$ \\ ${ }^{1}$ The Marketing Department, China united network communications co. LTD, Shandong branch, \\ China \\ ${ }^{2}$ Shandong Normal University, China \\ ${ }^{3}$ Student affairs office, No. 2 Middle School Attached to Shandong Normal University, China.
}

Keywords: Internet rumors; Laws and regulations; Governance; Countermeasures.

\begin{abstract}
Internet rumors can cause huge social harm and negative effects, not only seriously interfere with people's work and life, but also seriously damage the authority image of the government and the credibility of the government. Therefore, the management of the Internet rumors is urgent. First of all, we need to strengthen the capacity and awareness of the public and Internet users to distinguish between authenticity and falsehood in the face of all kinds of complicated and inflexible network information, do not blindly follow and believe it and maintain their self-judgment and understanding; Second, the administrative agencies must play a leading role in the management and control of online rumors, strengthen management practices and supervise the implementation; Finally, the practical measures should be taken to strengthen the related laws and regulations on the spread and harm of the Internet rumors.
\end{abstract}

\section{Introduction}

With the continuous development and popularization of the Internet, the Internet platform has become an increasingly important way for people to obtain social hot spots and understand current political information. The Internet is becoming an important stage for information publishing. But while people are enjoying the convenience brought by the Internet, it has also caused many unexpected misleading, deceit and even harm. Some Internet users, who lack legal consciousness and social responsibility, disseminate various types of false rumor information to confuse the public's attention and interfere with various purposes, or even mislead the public to discriminate and judge the information. It can be said that Internet rumors not only affect the daily life and work of the people, but even destroy the authority and credibility of the government.

On April 17, 2014, the heated case that "Qin Huohuo" (formerly known as Qin Zhihui) use Internet rumors to libel and stir up trouble has been first instance court verdict after a relatively long period of investigation. The defendant "Qin Huohuo" was sentenced to libel and other charges, a total of 3 years in prison, and he said he would not appeal. On September 9, 2013, the Supreme Court and the Supreme Procuratorate released the Interpretation on Several Issues Concerning the Application of Law in

Handling Criminal Cases such as Use Information Networks to libel, which provides that libel can be sentenced over 500 retransmissions. In the "Qin Huohuo" case, the Internet virtual rumors transmitted over 500 times, libeled many people, and the social impact was extremely bad, which constituted libel. In addition, the court held that "Qinhuohuo" made use of social software to deliberately fabricate fake information such as," The Ministry of Railways implemented a high amount of compensation for foreign passengers in motor vehicle accidents" and made himself hype through hot events, which constituted the crime of creating disturbances.

The whole trial process of "Qin Huohuo" case has received social attention and discussion, which made people pay more attention to the problem of Internet rumors. The Internet world cannot escape from the law. Any freedom of speech must be under the rule of law, system and morality. Anyone who 
goes beyond the norm will be severely punished. The margins to be used for your paper are as follows: In Word click on "File"; go to "Page Setup"; go to "Margins".

\section{Social Harm of Internet Rumors}

\subsection{Internet Rumors Erode the Social Trust System}

Internet rumors tend to be more negative social events. As the negative events are more likely to reach people's negative emotions, triggering social fluctuations in the mood, they can quickly spread the rumors and distort the truth of the matter. Therefore, when the similar events occur, the Internet rumors are often transmitted as facts. Even after clarification, it is difficult to gain universal recognition. People have often been blinded by their eyes, selectively believe rumors and ignore the truth of the matter, which makes people's trust in the society crack or even shake and then magnify the dark side of the society. In this process, contradictions are intensified, social stability is seriously damaged, and people lose confidence in the social and state functional departments.

\subsection{Cause Public Panic in Society, Destroy Social Order and Stability}

In 2010, an earthquake rumor in Shanxi Province caused millions of people to go out the city and take shelter; In 2011, the rumor of the spread of nuclear radiation in Japan caused the "salt rush" and "salt shortage" in China; In May 2011, Maya civilization on the rumor that 2012 was Doomsday triggered a huge social panic and strange social monster, these Internet rumors have caused many unnecessary negative effects and losses. Taking the rumor of the 2010 Shanxi Province earthquake as an example, the shadow of the 2008 Wenchuan County earthquake still lingered in people's minds, this rumor of earthquake triggered a great public panic about natural disasters. Shortly before this event, the Shanxi Datong just took a 4.8 magnitude earthquake, and the frequent natural disasters caused the people to panic. Even in the face of small possibilities, people dare not experience great risks. The whole city is out to avoid the earthquake, causing serious traffic jams, urban traffic system paralysis and serious damage to the normal social order.

\subsection{Mislead the Mainstream Values of Society}

With the openness and transparency of social information and the decline of the difficulty that people participate in social events, people's enthusiasm and initiative in participating in public events have been increasing. However, at the same time, due to the need of the process system and being responsible for information, government departments have some delays in the information disclosure and handling for public hot events, which also allows some Internet users to take the opportunity to change, disseminate and spread related information about the event, published unfair remarks, and then form various types of Internet rumors, induce public opinion trend, incite people's emotions, trigger panic and dissatisfaction in society and meet their own ulterior desires. Because the lack of the ability to discriminate and verify Internet rumors and Group psychology, the ordinary people are influenced by huge public opinion and can only obtain one-sided information. The original values and identification system will be shaken.

\subsection{Damage the Reputation of Citizens, Infringe the Rights and Interests of the People}

Internet rumors do not falsify facts and distort public events, but also defame the personal image of citizens. Some Internet users lacking legal awareness and sense of responsibility may distort facts, fabricate lies, attack and frame others maliciously, ang damage their reputation and image in order to satisfy vanity, gain an eye or seek private interest, which result in huge loss of reputation and mental distress to others, and affect others' work, study, life. For example, some people have spread rumors on the Internet, falsely saying that a national model of label was involved in a corruption incident. Finally, although the incident was clarified, and the rumor proved to be unwarranted, it still objectively impaired people's trust in the honor of national model of label and undermined the citizen's own reputation. 


\section{The Cause of Internet Rumor}

\subsection{Network Operators Lack of Sufficient Supervision}

Network operators are those who provide network services, they provide network services and naturally shoulder the functions and responsibilities of supervising the normal operation of the network. However, with the popularization and development of the Internet, the number of netizens in our country is getting more and more. As a result, many new problems have been caused. Internet rumors are undoubtedly a very important and significant issue. At present, the domestic network has not established a network real-name authentication system, so many Internet users can make irresponsible remarks at any time through the Internet, which cause many statements framing others' reputation, wantonly attacking the government and fabricating controversial events. These Internet rumors not only seriously damage the normal environment of the online society, but also affected the social atmosphere and normal public order.

\subsection{Citizens Lack of Awareness of Moral Consciousness and Scientific Rationality}

Civic Morality is the moral standard that all citizens must observe in daily life. At present, our society has not yet formed a civic morality system that is consistent with the special national conditions in our country. In the face of public events, people lack of thinking, have strong group psychology and is easy to be incited, inadvertently become participants in the Internet rumor spreading, or even the initiator. It is not only helpless to solve the incident, but also undermine the stability of social order, and contribute to the spread of Internet rumors and the adverse consequences. While scientific knowledge and rational consciousness is an important means to keep calm, and gain a correct understanding in the face of Internet rumors.

\subsection{Imperfect Laws, Regulations and Related Systems}

The network society is an extension of the society through the network technology. It is a projection of the society in the network information technology. It should accept the management of relevant laws, regulations and systems in the society. However, the legal system in our country is still in the process of continuous replenishment, construction and improvement, there are some loopholes, which gives a lot of criminals an opportunity to take advantage of. In the process of continuous development and rise of the Internet, due to the rapid development and the ever-changing network technology, the construction and improvement of the law cannot keep up with the development of the network in a timely manner, and thus vulnerabilities are more likely to occur.

\section{Internet Rumors Governance}

Internet rumors have infiltrated people's daily life and work, which has brought tremendous negative social hazards. Therefore, it is imperative to discuss and find the governance and preventive measures of Internet rumors.

\subsection{Formulate Relevant Laws, Regulations and Policies Contrapuntally}

The laws and regulations of a country are the necessary guarantees to safeguard the long-term peace and stability of the entire society. The Internet rumors are so widespread, the lack of strict punishment and management measures for the rumor is one of the important reasons. In foreign countries, the government severely punish those who spread the Internet rumors. Some countries, such as Singapore, even whisk people who spread rumors. However, the socialist legal system in our country is still constantly under construction and improvement. There is no strict legal laws and penalties for Internet rumors, which condone the indiscriminate rumors to some extent. Therefore, the continuous improvement of the relevant laws and regulations on Internet rumors and the establishment of disciplinary mechanisms are the first move. The strict punishments of the rumors can make people feel fearful and not be able to do anything.

\subsection{Establish the Network Real-Name Certification System as Soon as Possible}

The anonymity and virtuality of the network platform gives everyone an irresponsible speech environment in the dark corners. And there is no punishment after the speech, and no one even knows who makes a speech, which undoubtedly contributes to the spread of Internet rumors. Therefore, we 
must establish the network real-name certification system as soon as possible, so that users have a sense of social responsibility and self-consciousness in the Internet, which have constraints on their own speech and behaviors, and respect for others. As in real society, abide by the constraints of laws and institutions, abide by the rules and order of the network society, and be responsible for their own speech and behaviors. This is of great help to govern the Internet rumors, and at the same time, it can greatly facilitate investigate the sources of Internet rumors, thus purifying the network environment and establishing a social network order.

\subsection{Strengthen Citizen's Network Moral Construction}

Internet society is highly open, high degree of freedom and with low barriers to entry which brings a lot of convenience to people. However, at the same time, some low-quality information also enters the people's attention. Spam, fake websites and online scams and so on are endless. It is the lack of the moral sense of the network users, which seriously damages the network order. The Internet is a part of life, it is still a society microcosm of people gathering, the main participants are still people. Therefore, we still should observe social order and morality. Although morality is only an invisible soft constraint, it is also the most powerful constraint. Therefore, we must strengthen people's network moral construction.

\subsection{Strengthen Humane Quality Education and Cultivate Civic Responsibility}

In many Internet rumors events, there are a lot of people who are only bored for a moment, or win the eye joining the team of spreading Internet rumors. This is a manifestation of the lack of public humanities and civic responsibility. We should step up the sense of masters and social responsibility of citizens, get rid of low-grade tastes, and establish a sense of mission and responsibility toward the country and the nation. Treat the Internet in a rational manner and bind yourself with responsibility to infect others.

\section{Conclusion}

In today's social environment, due to the continuous improvement and popularization of the Internet and the constant advancement of technology, the information and data we receive are increasing exponentially, so this has also become an era of "big data explosion." On the one hand, people's horizons have gained tremendous openness and growth because of this information. People's lives have also gained a lot of convenience. At the same time, they have promoted the historical process of China's modernization and economic construction. However, every coin has two sides, we need a dialectical view of the problem. On the other hand, the network has virtualization, low access threshold and self-opening. If there is no effective regulation and management of information and users, there will be many negative impacts. In recent years, as the number of cases caused by Internet rumors increases and the results are different from each other, the trend intensifies and seriously disrupts the people's normal life and the stability of social order. People need to take the initiative to strengthen their own quality and legal awareness, enhance the ability to distinguish information. And the government departments should also conduct the correct guidance] of the Internet public opinion and establish an effective regulatory system, which is of great significance for maintaining social stability and promote social progress.

\section{Acknowledgements}

This work was supported in part by the National Natural Science Foundation of China (No. 61170038, 61472231, 71701115), the National Social Science Foundation of China (No. 14BTQ049), the Shandong Natural Science Foundation (ZR2017MF058), and Special project for Internet development of social science planning special program of Shandong province (17CHLJ23). 


\section{References}

[1]. Chen Z C. An Analysis of the Features of Internet Rumors from the Psychological Perspective. Journal of Educational Institute of Jilin Province, 2010(1):106-108.

[2]. Shen Y N. Internet rumor spread research. Southeast Communication, 2008(12):60-61.

[3]. Ke G X, Chi Y K, Wang B. Dissemination mechanism and countermeasure of network rumor in extraordinary period. Science of Social Psychology, 2009(1):29-33.

[4]. Zuo W N. Internet rumor spread research. Graduate School of Chinese Academy of Social Sciences, 2006.

[5]. Liu J. "AIDS female" Yan Deli Events The tragedy of infringement in the Internet age. http://law.southcn.com/c/2009-10/29/content_6150371.htm, 2009-10-29.

[6]. Liu G J. On Network Supervision and Its Institutional Construction. Lingnan Journal, 2011(1):10-14.

[7]. Li G C. On Internet Society and Cultivation of Internet Citizenship Consciousness. Journal of Hubei Administration Institute, 2010(6):78-81. 